\title{
A Recepção dos Códices de Nag Hammadi: Gnose e Cristianismo no Egito Romano da Antiguidade Tardia.
}

\author{
The Reception of the Nag Hammadi Codices: Gnosis and \\ Christianity in Late-Antique Roman Egypt.
}

\author{
Julio Cesar Dias Chaves* \\ Louis Painchaud ${ }^{\star *}$
}

RESUMO

Os Códices de Nag Hammadi começaram a despertar o interesse dos estudiosos do cristianismo antigo e das religiões no Império Romano já alguns anos depois de sua descoberta em 1945. Esses códices, geralmente associados ao fenômeno religioso chamado de gnosticismo, são não somente uma demonstração da diversidade do cristianismo no Império Romano, mas também um exemplo peculiar da transmissão e recepção de textos cristãos na Antiguidade tardia. Se os textos que integram os códices em questão foram provavelmente compostos em grego entre os séculos II e III, nas mais diversas localidades do Império, o que se tem hoje são traduções coptas compiladas no Egito na segunda metade do séc. IV. O gosto natural pelo mais antigo e a busca pela conjuntura dita gnóstica levaram os historiadores a priorizarem o estudo do contexto original grego de composição desses textos. No entanto, nas últimas décadas, o interesse pelo contexto de compilação dos escritos em questão tem crescido consideravelmente; o presente artigo se inscreve nessa perspectiva, sugerindo uma nova abordagem que, por meio da comparação literária e da teoria da recepção, busca explicar como e porque os textos de Nag Hammadi foram compilados e lidos no Egito da Antiguidade tardia.

Palavras-chave: Nag Hammadi, cristianismo antigo, Gnosticismo, monasticismo, teoria da recepção.

\footnotetext{
Doutorando em Ciências das Religiões pela Université Laval, Québec, Canadá

"* Professor titular de História do Cristianismo Antigo e diretor de pós-graduação da Faculdade de Teologia e Ciências das Religiões da Université Laval, Québec, Canadá.
} 


\section{ABSTRACT}

The Nag Hammadi Codices have been calling the attention of scholars of early Christianity and religions in Roman Empire almost since their discovery in 1945. These codices, generally associated with the so-called ssticism, are not only an example of the religious diversity of Christianity in the Roman Empire, but also a uliar illustration of the transmission and reception of Christian texts in Late-antiquity. The texts copied in codices in question were probably composed in Greek somewhere between the second and third turies, in many different locations in the Empire, but what we have today are Coptic translations compiled :gypt, in the second half of fourth century. The natural preference for the oldest and for the so-called sstic conjecture, lead scholars to prioritize the study of the original context of composition of these texts. vever, the last decades saw a growing interest for the study of the context of compilation of these texts in itic. This article intends to suggest a new approach and methodology to this kind of study in light of the ory of reception. The goal is to provide scholars with a method that may help us to understand how these is may have been interpreted by Coptic readers in Late-antique Egypt.

Keyword: Nag Hammadi, early Christianity, Gnosticism, monasticism, theory of reception.

\section{Considerações Preliminares}

O Egito da antiguidade tardia presenteou os historiadores com diversos conjuntos de manuscritos importantíssimos para o entendimento da pluralidade religiosa do Império Romano, principalmente quando se trata do cristianismo e de algumas de suas manifestações marginais. A quantidade de manuscritos cristãos que podem ser datados entre os séculos IV - principalmente após o fim da grande perseguição liderada pelo imperador Diocleciano - e VIII encontrados no Egito é realmente digna de nota; obviamente, tal abundância se deve ao clima seco do Egito, altamente propício para a conservação de manuscritos. Do que foi preservado em grego, poder-se-ia citar os incontáveis papiros de Oxyrhyncus ${ }^{1}$ e códices bíblicos (MILNE; SKEAT, 1963), como o Sinaiticus e o Alexandrinus, por exemplo. No tocante ao copta, língua vernácula do Egito na época romana, a quantidade de manuscritos é ainda maior; dentre estes, poder-se-ia destacar os textos maniqueístas de Medinet $\mathrm{Madi}^{2}$, o recentemente publicado Codex Tchacos, ${ }^{3}$ ou ainda os inúmeros textos monásticos preservados nas mais diversas bibliotecas dos mosteiros do Alto Egito, como o famoso monastério Branco, nas proximidades de Sohag. ${ }^{4}$ Todos os manuscritos citados, tendo sido encontrados em diferentes localidades do Egito, testemunham a pluralidade do cristianismo no país durante as épocas romana e bizantina.

\footnotetext{
${ }^{1}$ Uma boa introdução aos papiros de Oxyrhynchus pode ser encontrada em Blummel (2012).

2 Para uma introdução a esses manuscritos, ver Robinson (2013).

${ }^{3}$ Esse codex ficou famoso por conter o célebre Evangelho de Judas. Sobre a descoberta do volume em questão. Dias Chaves (2015b).

${ }^{4}$ Para se ter um panorama dos manuscritos coptas dos quais dispomos hoje. (DIAS CHAVES, 2015a, p. 59-78).
} 
Outro conjunto de manuscritos provenientes do Egito e compilados durante a dominação romana - muito provavelmente na segunda metade do séc. IV - tornou-se especialmente famoso por conter apócrifos cristãos que mencionam personagens célebres dos primórdios do cristianismo, como Paulo, Pedro, Filipe, Maria Madalena, Tomé, Tiago, o justo, e o próprio Jesus, por exemplo; trata-se dos códices de Nag Hammadi. ${ }^{5}$ Há cerca de 70 anos, os códices de Nag Hammadi têm chamado à atenção de diversos estudiosos das áreas de estudos bíblicos, cristianismo antigo e também dos especialistas em religiões no Império Romano. ${ }^{6} \mathrm{O}$ conjunto de manuscritos antigos encontrados nas proximidades da cidade moderna de Nag Hammadi, na antiga região de Chenoboskion, Alto Egito, propiciou aos estudiosos do cristianismo uma série de textos até então desconhecidos. Esse tesouro descoberto por acaso em 1945 (ROBINSON, 1981) é composto de cinquenta e um textos - dentre os quais trinta e seis eram até então desconhecidos - escritos em copta, heterogeneamente distribuídos em treze códices de papiros com coberturas de couro. Embora os manuscritos tenham sido fabricados no séc. IV acredita-se que os textos neles contidos sejam traduções coptas de obras originalmente compostas em grego entre os séculos II e $\mathrm{III},{ }^{7}$ nas mais diversas localidades do Império Romano, na maioria das vezes, difíceis de serem precisadas ou sequer vislumbradas. ${ }^{8}$

Não é segredo que os primeiros estudiosos que tiveram contato com esses textos associaramnos a doutrinas religiosas marginais do cristianismo primitivo, especialmente aquela que se convencionou chamar de "Gnosticismo", intensamente denunciado e combatido ainda na Antiguidade pelos ditos heresiólogos, tais quais Irineu de Lyon, ${ }^{9}$ Hipólito de Roma, ${ }^{10}$ Tertuliano ${ }^{11} \mathrm{e}$ Epifânio de Salamina, ${ }^{12}$ por exemplo. Em uma das primeiras descrições do conteúdo da descoberta, por exemplo, o estudioso Jean Doresse falou em "livros secretos dos gnósticos do Egito" (DORESSE, 1958). Desde então, a chamada "Biblioteca de Nag Hammadi" tem sido geralmente chamada de biblioteca gnóstica. ${ }^{13}$

Não se pode negar que muitos textos que fazem parte dos códices de Nag Hammadi apresentam doutrinas bastante similares àquelas combatidas pelos heresiólogos cristãos dos séculos II e III, como os citados acima; doutrinas estas convencionalmente chamadas de gnósticas pelos estudiosos modernos. Mas a quantidade de textos que não fazem uso direto dessas

\footnotetext{
${ }^{5}$ Para uma introdução à chamada Biblioteca Copta de Nag Hammadi. (DIAS CHAVES, 2015a).

${ }^{6} \mathrm{Um}$ caso interessante diz respeito aos chamados "Apocalipses Setianos de conteúdo filosófico", preservados em meio aos textos de Nag Hammadi. Esses textos misturam a tradição judaica de apocalipses de viagem ao além com neoplatonismo e são um testemunho de suma importância para a compreensão do contato entre cristianismo, judaísmo e filosofia no mundo romano. Sobre a questão, ver Dias Chaves (2007).

${ }^{7}$ A exceção é o fragmento da República de Platão (NH VI, 5)

${ }^{8}$ Uma das exceções talvez seja o Apocalipse de Pedro (NH VII, 3) que, segundo sugestão de Pearson, pode ter sido composto no próprio Egito (PEARSON, 1997, p. 93).

${ }^{9} \mathrm{Em}$ sua célebre obra, Contra as Heresias, composta em grego no séc. II, mas totalmente preservada apenas em latim.

${ }^{10} \mathrm{Na}$ sua obra conhecida como Elenchos

${ }^{11}$ Em obras como De praescriptione hereticorum, por exemplo.

${ }^{12}$ No célebre Panarion.

${ }^{13}$ As edições críticas em inglês dos textos de Nag Hammadi e do Codex de Berlim - publicadas ao longo dos anos 70 e 80 - foram posteriormente reunidas em uma reedição de cinco volumes. $O$ fato de essa reedição ter sido chamada de "Coptic Gnostic Library" é sintomático. O título da coleção franco-canadense de edições críticas dos textos de Nag Hammadi - Bibliothèque copte de Nag Hammadi - foi muito mais prudente nesse sentido, evitando referências diretas ao gnosticismo.
} 
doutrinas, ou mesmo uso algum, não pode ser negligenciada. Se levarmos em conta a definição clássica e simples de "gnosticismo" (JONAS, 1958; WILLIAMS, 1996; KING, 2003), segundo a qual existiriam duas divindades, uma divindade superior e uma divindade inferior, esta última responsável pela criação do mundo material e geralmente identificada com o deus das Escrituras judaicas, ${ }^{14}$ uma quantidade considerável de textos de Nag Hammadi não poderia ser rotulada de gnóstica, inclusive o célebre Evangelho de Tomé, por exemplo. ${ }^{15}$

Esse tipo de precisão consiste no primeiro passo na tentativa de avaliar os códices de Nag Hammadi de uma maneira mais clara e exata. Rotulá-los de "biblioteca gnóstica" não faz jus à sua pluralidade. Outro passo importante em direção a uma análise mais precisa dos textos que integram os códices de Nag Hammadi consiste na identificação de ao menos dois contextos de transmissão diferentes desses escritos. Como mencionado acima, acredita-se que de maneira geral os textos em questão foram originalmente compostos em grego, durante os séculos II e III. O que se tem hoje, no entanto, são traduções coptas, conservadas em códices fabricados no sul do Egito provavelmente na segunda metade do séc. IV.

Desde a descoberta dos textos, as análises dos estudiosos preocuparam-se basicamente com seus contextos originais de composição, o contexto supostamente gnóstico. Os textos de Nag Hammadi foram usados, por exemplo, para discutir as origens do cristianismo, as manifestações marginais dessa religião, e alguns escritos, em particular o Evangelho de Tomé, chegaram até a ser equivocadamente considerados como sendo evangelhos primitivos que poderiam remontar até à época de redação do Novo Testamento. No entanto, pouquíssimos estudiosos dedicaram tempo ao estudo do segundo contexto citado acima, o contexto copta do séc. IV, responsável pela conservação dos textos.

William Adler emitiu um alerta sobre um fato similar em relação ao estudo dos chamados pseudepígrafos judaicos; uma parte considerável desses textos - mesmo tendo sido produzidos em contextos relativamente antigos - foi preservada somente em línguas utilizadas por cristãos da antiguidade tardia ou alta Idade Média, tais quais o etiópico e o eslavônico, por exemplo. ${ }^{16}$ Isso demonstra que esses textos passaram por complexos processos de (re)transmissão, (re)edição e recepção. No entanto, raramente os estudiosos se interessam por esses processos, buscando a todo custo estabelecer um "texto original" para estudar somente seus contextos originais de composição. Na maioria das vezes, o fato de somente versões ou traduções tardias terem sido preservadas é visto - usando as palavras do próprio Adler - como um "lamentável acidente da

\footnotetext{
${ }^{14}$ Elementos como, por exemplo, "conhecimentos restritos a um grupo de eleitos", "visão negativa do mundo material" e "o envio de um salvador celeste para libertar os escolhidos" são genéricos demais para serem exclusivamente atribuídos a uma pretensa religião gnóstica, fazendo-se presentes nas doutrinas de diversas outras religiões e inclusive do próprio cristianismo de maneira geral, não podendo, portanto, ser usadas como traços de distinção.

${ }^{15}$ Para que se possa ter um panorama sobre a diversidade dos textos de Nag Hammadi, bem como sobre suas filiações teológico-doutrinais, consultar Poirier (1986). Ver ainda Dias Chaves, (2015a, p. 21-58).

${ }^{16}$ Exemplos elucidativos podem ser encontrados na chamada literatura enóquica, cujos textos, mesmo tendo sido originalmente compostos em contextos arcaicos, foram conservados em línguas da Antiguidade tardia geralmente usadas por cristãos; é o caso do Apocalipse Etiópico de Enoch e do Apocalipse Eslavônico de Enoque, por exemplo.
} 
história", a única alternativa que restou para o estudo dos contextos e autores originais desses escritos (ADLER, 1996, p. 2).

Mentalidade análoga tem prevalecido na pesquisa sobre os textos de Nag Hammadi. Como não se tem acesso aos originais gregos, as versões coptas foram usadas quase que exclusivamente para o estudo do "gnosticismo" nos sécs. II e III e para avaliar as origens do cristianismo ou a busca pelo Jesus histórico. O contexto copta de compilação desses textos foi pouco analisado. A quantidade de estudiosos que se perguntou como, porque e para que os textos em questão foram traduzidos e conservados em copta, circulando no sul do Egito no séc. IV é restrita. ${ }^{17}$ Nos parágrafos abaixo, procurar-se-á apresentar um breve resumo da história da pesquisa sobre o tema em questão, visto que seria impossível falar de todas as contribuições feitas a respeito desse tópico em um único artigo.

\section{Dos aspectos materiais à possibilidade de uma origem monástica: breve história da pesquisa}

Até à década de 80 , um número relativamente restrito de estudos pontuais sobre o contexto de compilação dos códices de Nag Hammadi havia sido realizado. Os primeiros estudos procuraram analisar as características materiais dos códices. Foram os casos, ainda na virada da década de 50 para a década de 60, de van Regemorter (VAN REGEMORTER, 1960) e Doresse (1961), que analisaram e descreveram as encadernações dos códices. Nas décadas de 70 e 80, foi a vez de se analisar os fragmentos de papiros usados na parte interna das capas de couro dos códices (BARNS, 1975; BARNS; BROWNE; SHELTON, 1981). Esses fragmentos de papiros eram usados para reforçar as capas dos códices, prática relativamente comum na fabricação de códices na Antiguidade tardia (GAMBLE, 1995; HAINES-EITZEN, 2000; BAGNALL, 2009).

Paralelamente, outros estudos procuravam elucidar quem teria sido responsável pela fabricação e utilização dos códices de Nag Hammadi. A ideia de uma comunidade puramente gnóstica vivendo no Egito copta do séc. IV foi logo rejeitada, devido basicamente à diversidade doutrinal dos textos que integram os códices, mas também ao fato de o gnosticismo ser uma realidade relativamente superada no cristianismo Egípcio do séc. IV. ${ }^{18}$ A primeira sugestão substancialmente consistente sobre os proprietários dos códices de Nag Hammadi foi feita por ninguém menos que James Robinson, que propôs que eles tivessem pertencido a membros de

\footnotetext{
17 Um bom estado da questão pode ser encontrado em Lundhaug e Jenott, no prelo.

${ }^{18}$ Em Panarion 26, 17, 4-9., Epifânio de Salamina, no séc. IV, alega que encontrou mulheres gnósticas no Egito que tentaram seduzi-lo. No entanto, Epifânio não precisa o que ele quer dizer exatamente com "gnósticas" e tal caracterização pode ser simplesmente interpretada como uma maneira de definir seus oponentes como hereges, rotulando-os com uma categoria relacionada à heresia. De qualquer maneira, o relato em questão é relativamente isolado e não é suficiente para demonstrar que existia um número considerável de "gnósticos" no Egito do séc. IV.
} 
comunidades monásticas pacomianas com certas tendências gnósticas; esses monges teriam vivido dentro dos mosteiros pacomianos, ${ }^{19}$ até que a crescente pressão eclesiástica em favor da ortodoxia os expulsasse. Essa busca pela ortodoxia nos mosteiros pacomianos teria tornado impossível a aceitação desse tipo de texto dentro dos próprios ambientes monásticos, o que obrigou seus proprietários a se livrarem deles, colocando-os num vaso de argila para que fossem enterrados (ROBINSON, 1974).

Os estudiosos que se dedicaram a analisar a questão posteriormente levaram a sugestão de Robinson em consideração, mas de modos diferentes. Tal sugestão ganhou força com as análises preliminares dos fragmentos de papiros usados para reforçar as coberturas de couros dos códices; Barns chegou a afirmar categoricamente que, devido ao conteúdo desses fragmentos e ao fato de não haver outras confederações monásticas atuando na região, poder-se-ia concluir que os códices foram, de fato, fabricados por monges pacomianos (BARNS, 1975, p.13). Durante a década de 70, e, em alguns casos, até posteriormente, essa sugestão predominou entre aqueles poucos que se dedicaram ao estudo em questão. Houve, portanto, quem aderisse à ideia de monges heterodoxos vivendo dentro dos mosteiros pacomianos (SCHOLTEN, 1988), mas houve também quem sugerisse que o caráter altamente heterodoxo dos textos era simplesmente inconciliável com o que se sabe sobre o monasticismo egípcio - inclusive o pacomiano - e que os códices só poderiam ser compreendidos como sendo uma espécie de biblioteca heresiológica; ou seja, os textos de Nag Hammadi teriam sido usados pelos monges sim, mas não para sua própria edificação espiritual, mas para que estes conhecessem e combatessem heresias (SÄVE- SÖDERBERGH, 1975). ${ }^{20}$

No início da década de 80 , no entanto, análises mais precisas dos fragmentos de papiros demonstraram que muitos deles não tinham necessariamente background monástico (BARNS; BROWNE; SHELTON, 1981), o que fez com que alguns estudiosos revessem a questão. Foi o caso, por exemplo, de Armand Veilleux que, em dois artigos publicados no início da década de 80, questiona-se sobre a ausência de atestação para comprovar a possibilidade de ligação dos códices de Nag Hammadi com o monasticismo. Veilleux discute particularmente a famosa Carta Festiva de 367 de Atanásio de Alexandria ${ }^{21}$ - na qual o famoso patriarca define quais os livros deveriam fazer parte do cânon bíblico. Tal carta poderia ser a prova de que livros apócrifos teriam sido definitivamente banidos dos mosteiros. Veilleux, no entanto, argumenta que nada pode comprovar tal fato (VEILLEUX, 1984, 1985). Em favor de Veilleux, poder-se-ia acrescentar ainda que existem fontes que comprovam que apócrifos continuaram a circular no sul do Egito até meados do século seguinte (ORLANDI, 1982).

\footnotetext{
19 Mosteiros pacomianos eram os mosteiros que pertenciam à comunidade monástica fundada por Pacômio, tradicionalmente considerado o fundador do monasticismo cenobita. Sobre essa questão, ver Rousseau (1985).

20 Tal possibilidade, que a princípio pareceu interessante e coerente, foi, no entanto, sendo gradualmente abandonada pelos estudiosos, devido à existência, por exemplo, de cólofons em alguns códices (ver, por exemplo, o cólofon do Codex III: NH III 69, 6-17; e o cólofon do Codex VII: NH VII 127, 28-32) que demonstram que os monges eram simpáticos aos seus conteúdos, mas ainda porque se sabe hoje que o monasticismo egípcio da antiguidade tardia incluso o pacomiano - era mais diversificado e pluralista do que se acreditava antes (GOEHRING, 1999).

21 Sobre as Cartas Festivas de Atanásio de Alexandria em específico, ver Dias Chaves (2015a, 48, p. 77-78).
} 
Em 1995, o russo Alexander Khosroyev publicou um livro inteiro sobre o assunto, até onde se pôde apurar, o primeiro unicamente dedicado a esse tópico (KHOSROYEV, 1995). Khosroyev também argumenta contra a possibilidade de uma origem e uma utilização monásticas para os códices de Nag Hammadi. A despeito das tentativas de se questionar a possibilidade de ligação entre os códices de Nag Hammadi e o monasticismo copta, uma parte substancial dos estudiosos que se dedica a esse tipo de pesquisa continua a acreditar que essa seja a possibilidade mais provável. Um livro chamado The Monastic Origins of the Nag Hammadi Library (LUNDHAUG; JENOTT, no prelo), fruto de um projeto realizado pela Universidade de Oslo, deve ser publicado em breve e defende mais uma vez a ligação dos códices de Nag Hammadi com o monasticismo egípcio. Trata-se do estudo mais recente sobre o assunto.

No tópico a seguir, serão brevemente discutidos alguns estudos que buscaram tratar de questões relativas aos possíveis contatos literários entre os textos de Nag Hammadi e a literatura copta da Antiguidade tardia, uma abordagem mais próxima da sugerida pelo presente artigo.

\section{A possibilidade de contatos literários entre os textos de Nag Hammadi e a Literatura Copta da Antiguidade Tardia}

Ainda na linha da possibilidade de existência de alguma ligação entre os códices e o monasticismo egípcio da antiguidade tardia, houve ainda quem procurasse apontar a existência de contatos literários entre os textos de Nag Hammadi e textos monásticos coptas, influenciados obviamente pela possibilidade de origem pacominana sugerida pelos estudiosos mencionados acima. Foi o que tentou fazer, por exemplo, Frederik Wisse no final da década de 70 em dois estudos (WISSE, 1978, 1979). No primeiro artigo, Wisse aponta uma série de barreiras à possibilidade levantada por Säve- Söderbergh (SÄVE-SÖDERBERGH, 1975) de que os códices de Nag Hammadi formariam uma biblioteca heresiológica, apoiando-se basicamente nos cólofons de alguns códices e símbolos decorativos que demonstram que os escribas eram simpáticos aos conteúdos dos livros que copiavam (WISSE, 1978, p. 436). No artigo do ano seguinte, Wisse centra suas análises na procura de linguagem mística nos textos de Nag Hammadi e na literatura monástica copta (WISSE, 1979).

Charles Hedrick foi outro que, influenciado pela ideia dominante da década de 70 , procurou identificar tendências gnósticas na versão grega de uma das mais famosas obras do monasticismo egípcio, a chamada Vida Grega de Pacômio, num artigo de 1980 (HEDRICK, 1980). O problema é que alguns dos motivos ditos gnósticos identificados por Hedrick em seu artigo são, na verdade, 
genéricos demais para serem necessariamente rotulados como tal; ${ }^{22}$ além do mais, como dito anteriormente, muitos dos textos de Nag Hammadi não são propriamente gnósticos.

A partir da década de 90, sem necessariamente tentar ligar os textos de Nag Hammadi a uma origem monástica, outros estudiosos - como, por exemplo, van der Vliet (1999) e mais recentemente Jenott e Pagels (JENOTT; PAGELS, 2010; JENOTT, 2013) - tentaram explorar a possibilidade de contatos literários entre os textos de Nag Hammadi e a literatura copta que circulava no Egito romano da Antiguidade tardia.

Por fim, não se pode deixar de mencionar uma importantíssima comunicação apresentada pelo coptologista Stephen Emmel no seminário que em 1995 comemorou os 50 anos da descoberta dos códices de Nag Hammadi23 (EMMEL, 1997). Na comunicação em questão, Emmel fala da transmissão dos textos de Nag Hammadi, postulando quatro fases para esse processo: o primeiro estágio seria o de pré-composição em grego, o segundo, o estágio de escritura em grego, o terceiro, o estágio de tradução do grego para o copta e o quarto o estágio monástico copta (EMMEL, 1997). No mesmo artigo, Emmel postula algo interessante sobre como as pesquisas sobre o contexto copta dos códices de Nag Hammadi deveriam proceder. Em suas próprias palavras:

Em relação às fases coptas de transmissão, há ainda uma tarefa óbvia que ainda não foi realizada exaustiva e consistentemente, i.e. a leitura dos códices de Nag Hammadi como parte da literatura copta [...] tal tarefa consiste em ler os textos exatamente como eles se encontram nos códices de Nag Hammadi em um esforço que visa reconstruir a experiência de leitura de quem quer que tenha possuído cada um dos códices. Essa leitura deveria ser realizada em total consonância com a literatura e a cultura coptas do alto Egito durante, digamos, o período que vai do séc. III ao séc. VII. Isso seria primordialmente uma iniciativa que levaria em conta o contexto copta, não tendo necessariamente nada a ver com as origens do cristianismo, nem com o "Gnosticismo" (EMMEL, 1997, p. 42). ${ }^{24}$

O valor dessa sugestão de Emmel é tamanho, a ponto de se poder dizer que ele praticamente inaugurou uma nova etapa nos estudos do contexto de compilação dos códices de Nag Hammadi, influenciando os trabalhos futuros. O próprio trabalho do presente autor foi influenciado pela premissa acima, inscrevendo-se nessa perspectiva.

\footnotetext{
${ }^{22}$ Como cegueira espiritual e salvação por meio do conhecimento de Deus, por exemplo.

${ }^{23}$ Coincidentemente, o assunto em questão foi novamente abordado pelo presente autor nesse ano, em outro seminário comemorativo, dessa vez celebrando os 70 anos da descoberta dos códices de Nag Hammadi, na Université Laval, Québec (DIAS CHAVES, 2015c). As comunicações desse seminário serão igualmente publicadas em breve.

${ }^{24}$ Traduzido livremente do inglês pelo presente autor.
} 
No tópico seguinte, serão feitas algumas considerações sobre a existência de subcoleções em meio aos códices de Nag Hammadi, bem como sobre a diferença entre produção e destinação dos códices.

\section{A diferença entre origem e destinação}

Em 1984, no prefácio da edição fac-símile dos códices de Nag Hammadi, Robinson já havia chamado falado das inúmeras diferenças na confecção dos volumes (ROBINSON, 1984). Tendo em vista tais diferenças, ele sugeriu a existência de subgrupos de códices. Assim sendo, de acordo com Robinson, seria possível dividir os códices em subgrupos, classificando-os de acordo com suas diferenças e semelhanças materiais (ROBINSON, 1984, p. 81-86).

Além das diferenças materiais na fabricação dos códices, (diferentes tipos de encadernações, cadernos de papiros e coberturas de couro), não se pode deixar de citar que diferentes escribas foram responsáveis pela cópia dos textos. Por fim, as diferenças dialetais substanciais existentes entre os códices ou subgrupos de códices não podem ser esquecidas. Tais diferenças demonstram que os subgrupos de códices foram copiados e fabricados em ambientes diferentes. Assim sendo, não se pode falar de uma origem única para os códices de Nag Hammadi, muito menos de um destinatário único.

Em princípio, existiriam ao menos quatro subgrupos de códices: um primeiro grupo formado pelos códices IV, VI, VIII, IX e talvez o V (características materiais semelhantes, ausência de textos repetidos, fragmentos de papiros nas capas formados por documentos oficiais, mesma escola de escribas); um segundo grupo formado pelos códices II e XIII (mesmo escriba, duas cópias idênticas do mesmo texto - o Escrito sem título sobre a origem do mundo - cada uma em um codex diferente - NH II, 5 e NH XIII, 2 - o que indica que eles foram produzidos para destinatários diferentes); um terceiro grupo formado pelos códices I, VII e XI (características materiais semelhantes e três escribas diferentes, sendo que dois deles copiaram trechos diferentes do Codex XI); e por fim, um quarto subgrupo, formado apenas pelo Codex III. Recentemente, essas questões foram detalhadamente discutidas por Painchaud (no prelo).

A existência de textos repetidos nos subgrupos de códices, além de outros pormenores apontados acima demonstra que eles foram produzidos para destinatários diferentes. ${ }^{25}$ Levando tudo isso em consideração, Painchaud sugeriu recentemente uma diferenciação entre produção e destinação dos códices de Nag Hammadi (PAINCHAUD, no prelo; PAINCHAUD, 2015). Com isso,

${ }^{25} \mathrm{O}$ alto custo de produção de livros na antiguidade torna extremamente improvável que uma mesma pessoa tenha pagado um escriba ou scriptorium para produzir mais de uma cópia do mesmo texto. Sobre os custos de produção de livros no Egito romano, ver Bagnall (2009, p. 50-69). 
ele quis dizer que se deve diferenciar esses dois aspectos porque nem sempre quem produz 0 códice é quem vai lê-lo. Por produção poderíamos entender, portanto, origem, por destinação quem o encomendou ou recebeu para lê-lo. Ao se perguntar, portanto, sobre a produção e a destinação dos códices de Nag Hammadi, pode-se resumir a resposta em uma palavra: diversidade. Diversidade de ambientes que produziram os códices ou subgrupos de códices primeiramente; em seguida diversidade no tocante aos destinatários; diversidade ainda no tocante às relações que os diferentes copistas tinham com os códices que estavam copiando e seus respectivos destinatários (PAINCHAUD, 2015, p. 1). Assim sendo, o estudo recente de Painchaud vai além da discussão das diferenças materiais entre os códices, levando em conta também as relações que os escribas tinham com os destinatários dos códices (PAINCHAUD, 2015; PAINCHAUD, no prelo).

Por exemplo, a nota do escriba no Codex $\mathrm{Vl}^{26}$ demonstra que os destinatários constituíam um grupo de pessoas e que o próprio escriba acreditava que eles já possuíam alguns textos herméticos, sem saber exatamente quais; além disso, pode-se concluir que o escriba não estava em contato direto com os destinatários, pois se fosse esse o caso, ele poderia ter conferido pessoalmente quais os textos eles já possuíam (PAINCHAUD, 2015, p. 4). Por fim, poder-se-ia inferir que o escriba em questão demonstra certa indiferença em relação aos textos que copia, já que se preocupa somente em justificar porque não copiou outros, mesmo tendo-os em seu poder. A relação entre o remetente e o destinatário parece ser meramente comercial, não aparentando ter absolutamente nenhum caráter religioso (PAINCHAUD, 2015, p. 5). O cólofon do Codex VII ${ }^{27}$ apresenta uma situação deveras diferente: o escriba se dirige ao destinatário usando uma fórmula piedosa, chamando-o de pai (espiritual), pedindo sua benção e demonstrando que havia entre eles um laço de devoção filial; eles se conheciam pessoalmente e tinham laços pessoais estreitos (PAINCHAUD, 2015, p. 9). A análise dos cólofons e notas deixados por escribas nos códices de Nag Hammadi pode, portanto, dizer bastante sobre aqueles que os leram, pode ajudar no estudo da recepção de seus textos no contexto que interessa aqui.

Posto isso, este artigo gostaria de ir além no tocante às duas fazes citadas acima: produção e destinação. Poder-se-ia acrescentar uma terceira fase, o destino final. Por destino final entende-se o estágio final dos códices, o estágio que os reuniu no vaso que foi enterrado nas proximidades da antiga região de Chenoboskion e descoberto séculos depois, em 1945. É obviamente impossível saber com quanta antecedência os códices foram reunidos antes de serem selados no jarro e enterrados. Não se sabe se eles passaram algum tempo juntos em alguma biblioteca qualquer, por exemplo, ou se foram reunidos somente para serem enterrados.

De qualquer modo, esses três aspectos da fase copta - a produção, a destinação e o destino final - demonstram a complexidade do contexto de compilação, circulação e consumo dos textos e

\footnotetext{
26 "Eu copiei este discurso dele. De fato, muitos outros (discursos) vieram a mim. Eu não os copiei porque pensei que eles tivessem chegado a vós. Ainda, hesito copiar estes para vós porque talvez eles já tenham chegado a vós, e isto poderia incomodar-vos. Já que os discursos dele que chegaram até mim são numerosos..." (NH VI, 65, 8-14).

27 "Este livro é (o livro) da paternidade. É o filho que o escreveu. Abençoe-me, pai. Eu te abençoo, pai. Em paz. Amém" (NH VII 127, 28-32).
} 
dos códices de Nag Hammadi. Tal complexidade torna possível a adoção de diversas abordagens para a análise e a compreensão da importância desses textos no contexto do Egito copta cristão. A seguir, será brevemente apresentada uma abordagem desenvolvida pelo presente autor abordagem essa colocada em prática em sua tese de doutorado - que se baseou na teoria da recepção e no comparatismo literário. Por meio dessas abordagens, procurou-se explicar como os textos de um dos códices em específico de Nag Hammadi - o Codex V - foi possivelmente lido, recebido e entendido no Egito copta cristão da Antiguidade tardia. De modo adjacente, tal entendimento pode ajudar a explicar como e porque cristãos coptas da Antiguidade tardia se interessaram por esses textos. Assim sendo, poder-se-ia entender um pouco melhor o motivo de esses textos terem sido preservados e consumidos em copta, a despeito de seus conteúdos tradicionalmente vistos como gnósticos - aparentemente tão distantes da realidade religiosa do Egito no séc. IV.

\section{Abordagem comparativa e teoria da recepção}

Como demonstrado anteriormente, Emmel sugeriu que se reconstituísse a experiência de leitura de quem possuiu cada um dos códices de Nag Hammadi. Esse apelo do célebre estudioso estadunidense constituiu a gênese das pesquisas de doutorado realizadas pelo presente autor. De certa forma, a abordagem proposta por Emmel é uma abordagem que procura avaliar a recepção dos textos de Nag Hammadi, ou seja, como eles eram lidos, entendidos e interpretados pelos leitores do Egito copta cristão da Antiguidade tardia. Na tentativa de atender ao apelo de Emmel, o presente autor tomou contato com estudos literários e descobriu a teoria da recepção de Hans $\mathrm{R}$. Jauss (1978).

Um dos mais importantes conceitos na teoria da recepção de Jauss é o chamado "horizonte de expectativas". Segundo esse conceito, um leitor qualquer, ao tomar contato com um novo texto o lê e o interpreta de acordo com pré-suposições e conhecimentos adquiridos a partir de outros textos que ele já conhecia anteriormente. Esses conhecimentos e pré-suposições adquiridos se modificam de um dado período para outro e são em grande parte ditados por questões históricas e culturais de cada época (JAUSS, 1978; BALDICK, 2008, p. 282-283).

Obviamente, as pré-suposições e conhecimentos adquiridos que influenciaram e definiram a compreensão e a interpretação dos leitores coptas da Antiguidade tardia que consumiram os textos de Nag Hammadi nos séculos IV e $V^{28}$ eram deveras diferentes das pré-suposições e conhecimentos adquiridos dos leitores de língua grega que conheceram esses textos em seus

${ }^{28}$ Pode-se incluir o século $\mathrm{V}$ nessa premissa porque apesar de os códices de Nag Hammadi terem sido fabricados na segunda metade do séc. IV, nada impede que eles tenham continuado a ser utilizados ao longo do século seguinte. 
contextos originais de composição, ainda nos séculos II e III. Isso significa, por exemplo, que é bastante provável que os leitores coptas da Antiguidade tardia não estavam preocupados com heresiólogos combatendo o gnosticismo, ou com a diferenciação entre o deus das Escrituras, criador do mundo material e o deus supremo. Suas preocupações diziam respeito a outras controvérsias teológicas, próprias de seu tempo - como o cisma meliciano e o arianismo, por exemplo - ou com novas realidades do cristianismo - como o surgimento e desenvolvimento do monasticismo. Sem dúvida, essas eram algumas das questões que influenciavam e ditavam a maneira como eles interpretariam os textos de Nag Hammadi.

Mas além desse contexto histórico e teológico, o que mais poderia ajudar a entender - de maneira mais precisa - como os textos de Nag Hammadi poderiam ter sido recebidos e interpretados pelos leitores coptas da Antiguidade tardia que tiveram contato com eles nos séculos IV e V? Em outras palavras, como é possível chegar a conhecer o "horizonte de expectativas" dos leitores de um dado período histórico - no caso específico do presente artigo, os leitores coptas da Antiguidade tardia? Segundo o próprio Jauss, por meio principalmente de normas próprias aos gêneros literários analisados e de relações implícitas entre a obra analisada e as demais obras que circulavam na mesma época (HOLUB, 1984, p. 60).

Ou seja, para conhecer o "horizonte de expectativas" dos leitores coptas da Antiguidade tardia que leram os textos de Nag Hammadi, é necessário antes conhecer intimamente a literatura que circulava na mesma época em que os códices foram compilados e circularam no Egito, i.e. presumivelmente os séculos IV e V. Tal afirmação pode parecer extremamente óbvia a princípio, mas na prática, nota-se que muitos estudiosos dos códices de Nag Hammadi - geralmente preocupados somente com o contexto original de composição, o contexto dito gnóstico - não se interessam por outros tipos de literatura que circulavam na mesma língua, região e época em que a coleção em questão foi compilada. Grosso modo, foram feitas comparações entre os textos de Nag Hammadi e os textos bíblicos, a literatura apócrifa e neoplatônica, por exemplo, mas se ignorou muitas vezes a possibilidade de se fazer comparações com outros textos que circulavam na mesma época e local nos quais os textos de Nag Hammadi foram compilados em copta. A título de exemplo, pode-se mencionar que comparações com a literatura monástica ${ }^{29}$ copta do séc. IV, por exemplo, são raras, apesar de a possibilidade de uma origem monástica para os códices ter sido uma das mais exploradas pelos estudiosos que se dedicaram à questão, como visto anteriormente.

Seguindo a pista da ligação dos códices com ambientes monásticos, poder-se-ia pensar num exemplo que ilustrasse brevemente a aplicação da abordagem proposta acima. Nada melhor do que procurar esse exemplo no mais famoso e estudado texto de Nag Hammadi, o Evangelho de Tomé, do Codex II. No logion 49 do texto em questão, é possível ler a palavra Greco-copta monakos,

\footnotetext{
${ }^{29}$ Por literatura monástica copta entende-se os textos certamente produzidos por e/ou para monges coptas da Antiguidade tardia, como, por exemplo, as hagiografias de monges como Pacômio e Antão (A Vida de São Pacômio e a Vida de Santo Antão), mas também as regras monásticas, instruções e catequeses.
} 
geralmente traduzida como "solitários." ${ }^{30}$ Essa tradução/interpretação do termo em questão provavelmente conviria se 0 foco fosse o contexto original de composição do texto; mas pensemos no horizonte de expectativas dos leitores coptas que leram esse texto no séc. IV, na época de florescimento do monasticismo, quando mosteiros se espalhavam pelo sul do Egito e incontáveis homens e mulheres saiam das cidades rumo ao deserto para se enclausurarem num mosteiro ou viverem como anacoretas, a ponto de Atanásio de Alexandria, em sua célebre Vida de Antão, ter dito que "o deserto se tornou uma cidade". ${ }^{31}$ Para os cristãos coptas do séc. IV, o monasticismo era uma realidade próxima e importantíssima - mesmo daqueles que não estavam diretamente envolvidos com este fenômeno - que influenciava a economia, a cultura e as práticas religiosas. ${ }^{32}$ Assim sendo, não seria absurdo pensar que esses cristãos coptas que leram o Evangelho de Tomé no séc. IV pensassem não num simples solitário ao lerem a palavra Greco-copta monakos - como a maioria das traduções modernas sugerem - mas num monge propriamente dito, ainda mais porque o logion no qual a palavra em questão aparece diz que os monakos encontrarão o Reino, o que coincidiria muito bem com a fama de modelo cristão de santidade da qual em geral gozavam os monges.

Comparações como a ilustrada acima, embora raras até pouco tempo, não são de forma alguma banais ou improdutivas. Elas podem demonstrar que existe muito mais em comum principalmente no tocante a temas e motivos literários - entre a literatura copta da Antiguidade tardia e os textos de Nag Hammadi do que se presume normalmente. A identificação desses temas e motivos comuns pode, portanto, levar a dois resultados:

1. Demonstrar que ambos os corpora podem ter despertado o interesse do mesmo público. Isso poderia advogar em favor da possibilidade de uma ligação com ambientes monásticos (seja na produção ou na destinação e/ou destino final), já que uma parte considerável da literatura que circulava em copta na Antiguidade tardia era produzida ou traduzida por monges e muitas vezes para monges. ${ }^{33}$ Essa comparação poderia ainda ajudar a esclarecer a cogitada incompatibilidade doutrinal entre os textos de Nag Hammadi e aquilo que se sabe sobre o cristianismo egípcio da Antiguidade tardia, o que levou alguns estudiosos a considerarem que os códices só poderiam ser entendidos como uma espécie de biblioteca heresiológica (SÄVE-SÖDERBERGH, 1975), ou ainda, como uma coleção não cristã. ${ }^{34}$ Como se verá em breve - com o

\footnotetext{
30 "Felizes os "solitários" e os eleitos, pois vós encontrareis o Reino" (Evangelho de Tomé, logion 49a). Stephen Emmel já havia chamado à atenção para esse exemplo em 2013, na ocasião do Seminário New Contexts for Old Texts, em Oslo. Deve-se a ele, portanto, esse pontual, mas ao mesmo tempo pertinente, exemplo.

${ }^{31}$ Vida de Antão § 14.

32 Um panorama dos impactos gerais no monasticismo no Egito pode ser conhecido por meio da obra de Wipszycka (WIPSZYCKA, 2009).

${ }^{33}$ Não é à toa que maioria dos manuscritos coptas conhecidos até meados do séc. XX foram descobertos em bibliotecas monásticas (SCHOLTEN, 1988, p. 172).

34 Por exemplo, em um artigo sobre livros cristãos no Egito e a tradição copta, Emmel opõe o gnosticismo ao cristianismo, deixando a entender que, pare ele, seriam duas religiões diferentes. O famoso coptologista diz claramente, inclusive, que ao longo de sua história, a literatura copta foi praticamente toda cristã, as exceções seriam alguns conjuntos de textos maniqueístas e gnósticos, entre eles, a Biblioteca de Nag Hammadi (EMMEL, 1998, p. 39). Khosroyev foi outro que relutou em admitir o caráter cristão dos códices de Nag Hammadi, sugerindo, de maneira deveras genérica, que eles tenham pertencido a uma comunidade religiosa qualquer (KHOSROYEV, 1995, p. 98).
} 
exemplo específico do Codex $\mathrm{V}$ - os leitores coptas da Antiguidade tardia podem muito bem ter demonstrado interesse não necessariamente pelo conteúdo doutrinal dos textos de Nag Hammadi, mas pela forma na qual esses textos foram escritos, utilizando-se de temas e motivos literários abundantemente presentes na literatura copta.

2. Entender melhor como os textos de Nag Hammadi eram lidos, recebidos e interpretados no contexto responsável por sua compilação, i.e. o Egito Copta do séc. IV. Em outras palavras, o conhecimento do significado de certos temas e motivos literários abundantemente presentes em textos coptas pode ajudar a entender como esses mesmos temas e motivos literários eram interpretados pelos leitores dos códices de Nag Hammadi.

Na tentativa de ilustrar melhor como se pode por em prática tal teoria, em seguidas serão feitas algumas considerações sobre um dos códices de Nag Hammadi, o Codex V.

\section{O Codex V: $O$ codex apocalíptico}

"Codex apocalíptico", assim o Codex $\mathrm{V}$ tem sido chamado pelos estudiosos - de maneira especial por Morard (1995, p. 341-357) e Rosentiehl e Kaler (2005, p. 149); tal epíteto se deve ao fato de o Codex $\mathrm{V}$ possuir ao menos quatro textos nomeados como "apocalipse" no manuscrito (Apocalipse de Paulo, Primeiro Apocalipse de Tiago, Segundo Apocalipse de Tiago ${ }^{35}$ e Apocalipse de Adão). O título do primeiro texto do Codex $\mathrm{V}$ não foi preservado, mas ele é tradicionalmente chamado de Eugnostos devido ao fato de existir no Codex III outra versão do mesmo, na qual o título aparece claramente (NH III, 90, 13-14). Além dos títulos de apocalipse, os textos do codex em questão estão cheios de temas e motivos literários que são geralmente associados à literatura apocalíptica, como visões fantásticas de seres celestes $^{36}$, viagens ao além ${ }^{37}$ e epifanias, ${ }^{38}$ por exemplo.

Em vista de um codex relativamente homogêneo do ponto de vista temático, portanto, e tendo sido certamente influenciado pelo assunto tratado em sua dissertação de mestrado, ${ }^{39}$ o presente

\footnotetext{
${ }^{35}$ No manuscrito do Codex V, o Primeiro e Segundo Apocalipses de Tiago possuem exatamente o mesmo título: "Apocalipse de Tiago". As designações de "Primeiro" e "Segundo" foram postuladas pelos estudiosos visando à praticidade, seguindo a ordem em que os textos aparecem no manuscrito.

${ }^{36}$ Como, por exemplo, no caso do Apocalipse de Adão, em NH V 65, 24-66,8.

${ }^{37}$ Como, por exemplo, no caso do Apocalipse de Paulo.

${ }^{38}$ Como, por exemplo, no caso do Primeiro Apocalipse de Tiago, em NH V 30,13-31,9.

39 Dissertação que definiu e analisou o corpus apocalíptico de Nag Hammadi e cujo título foi "The Nag Hammadi Apocalyptic Corpus: Delimitation and Analysis".
} 
autor não hesitou em comparar o Codex $\mathrm{V}$ com a literatura copta da antiguidade tardia. Tal comparação logo se mostrou extremamente produtiva, pois a quantidade de temas e motivos literários geralmente associados à literatura apocalíptica também abundava na literatura copta da Antiguidade tardia, em especial nas hagiografias (DIAS CHAVES, 2011).

O leitor copta da antiguidade tardia que lia essas hagiografias estava habituado, portanto, a ler sobre seres celestes mediando revelações, viagens ao além, epifanias fantásticas com seres brilhantes. Esse mesmo leitor poderia encontrar nas páginas do Codex $\mathrm{V}$ esses mesmos temas. Vejamos alguns exemplos práticos.

Um dos motivos literários mais comuns em textos apocalípticos de viagem ao além diz respeito ao fato de o visionário ser elevado ao céu - o que significa em termos práticos que ele não foi ao céu por suas próprias forças, mas foi arrebatado. De maneira geral, essa ação é expressa nos textos coptas pelo verbo autóctone тюрп. No Apocalipse de Paulo, pode-se encontrar um exemplo do motivo em questão quando o personagem pseudonímico Paulo, após se encontrar com um menino (que servirá como seu mediador celeste no decorrer da ascensão e que depois se identifica com o Espírito Santo), é arrebatado aos céus: "O [Espírito] ${ }^{40}$ Santo, que falava com [ele], arrebatou-

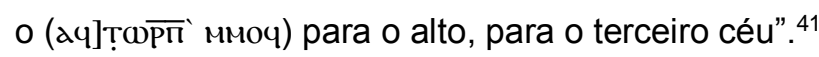

O mesmo motivo pode ser encontrado em diversas hagiografias coptas; de maneira geral, o monge que é personagem principal de uma hagiografia qualquer é arrebatado aos céus. Pode-se encontrar um exemplo na Vida Saídica de Antão; num determinado momento, depois de rezar, Antão é arrebatado aos céus e percebe que está sendo acompanhado por mediadores celestes: "Aconteceu num dia que ele (Antão), estando prestes a comer e levantando-se para rezar na nona hora, percebeu que estava sendo arrebatado em pensamento (едүторпі гмпєчгнт) [...] sendo guiado no ar por certos seres". ${ }^{4}$

Não seria absurdo pensar, portanto, que o mesmo leitor que se interessava pelos relatos de ascensão celeste que aparecem em hagiografias preservadas em copta - como a Vida Saídica de Antão, por exemplo - se interessasse pelos mesmos tipos de relato no Apocalipse de Paulo do Codex V. Além do mais, levando em conta a perspectiva da recepção, esse mesmo leitor - que tinha nos seus horizontes de expectativas as figuras heroicas de monges santos sendo arrebatados aos céus - provavelmente viria no personagem do Apocalipse de Paulo não um Paulo gnóstico contrário à ortodoxia que desafiava a hierarquia eclesiástica e que tentava escapar do criador do mundo material, mas um santo que, à semelhança de Antão, foi digno de ser elevado aos céus.

\footnotetext{
${ }^{40} \mathrm{Em}$ edições e traduções de textos coptas, os colchetes são usados para indicar que existem lacunas no manuscrito. Isso acontece porque nem sempre o estado de preservação dos manuscritos é bom. Por vezes, essas lacunas podem ser restituídas - algumas restituições são, obviamente, mais plausíveis que outras - mas edições e traduções de qualidade sempre indicam - por meio dos citados colchetes - que elas existem.

${ }^{41} \mathrm{NH}$ V 19, 20-25. Tradução feita diretamente do copta para o português pelo presente autor.

42 Vida Saídica de Antão § 65. Tradução feita diretamente do copta para o português pelo presente autor. Deve-se notar que nesse caso é utilizada uma variação dialetal do verbo тюрп (торп).
} 
Outro exemplo bastante elucidativo pode ser igualmente encontrado no fim do Apocalipse de Paulo, no momento em que o visionário chega ao fim de sua ascensão, adentrando o décimo céu (NH V 24, 6-8). No trecho em questão, Paulo entra no décimo céu e saúda os espíritos que já estão lá, os habitantes do local: "E nós subimos ao décimo céu. $E$ eu saudei (aī̄acnaze) meus companheiros espíritos". ${ }^{43} \mathrm{~A}$ cena poderia ser considerada absolutamente banal se não fosse o fato de ser possível encontrar esse motivo de forma abundante em diversas hagiografias preservadas em copta, em especial nas chamadas "paixões épicas". Nesses textos, que contam de maneira épica e lendária os martírios de cristãos na perseguição de Diocleciano (BAUMEISTER, 1972), os mártires morrem invariavelmente decapitados e muitas vezes suas almas são escoltadas até os céus por anjos e quando lá chegam, são saudadas ou saúdam os santos que já se encontram lá, semelhantemente ao caso do Apocalipse de Paulo. É o que acontece, por exemplo, nos Martírios dos Santos Apaioulle e Pteleme, cujo único manuscrito preservado encontra-se na Biblioteca Pierport Morgan. Nesse texto, após a morte de São Ptelemel, São Apaioulle é igualmente martirizado e ascende aos céus, onde se junta ao seu amigo e predecessor. A ascensão é descrita da seguinte maneira: "Os anjos vieram, tomaram sua alma e a arrebataram para o céu, e eles a fizeram saudar (аүтречаспаzе) os santos. Depois disso ele saudou (дудспаzе) o Apa Pteleme no reino de Jesus Cristo" (Pierpont Morgan Library M583, fol. 173 r ii). ${ }^{44}$

É perfeitamente plausível que os leitores coptas da Antiguidade tardia que leram o Apocalipse de Paulo conhecessem esse motivo literário por meio das hagiografias coptas. Assim sendo, mais do que um contato literário entre o Apocalipse de Paulo e esses textos, poderíamos postular que o fato de o herói chegar aos céus e saudar seus habitantes fazia parte do horizonte de expectativas dos leitores coptas que tinham contato com esses próprios textos. Mais do que isso, o fato de Paulo saudar os espíritos no décimo céu pareceria algo absolutamente normal, até esperado.

Outros exemplos interessantes podem ser encontrados nas aparições de seres celestes nos textos do Codex V. Como se sabe, a presença e aparição de anjos e seres celestes fantásticos em geral constitui um dos traços mais marcantes da literatura apocalíptica (COLLINS, 1979). Seria de se esperar, portanto, que em um codex cheio de apocalipses, esses tipos de seres aparecessem com frequência, e de fato é esse o caso. Mas outros tipos de literatura que circulavam em copta na Antiguidade tardia, em especial as hagiografias, também mostram vários anjos e seres celestes fantásticos.

No Apocalipse de Adão, por exemplo, é contado que Adão viu em sonho três seres fantásticos: "E eu dormi no pensamento do meu coração. E eu vi três homens diante de mim cuja aparência eu não conseguia reconhecer, já que eles não pertenciam ao poder do deus que [nos] [criou] (NH V 65,

\footnotetext{
${ }^{43}$ Tradução feita diretamente do copta pelo autor do presente artigo. Deve-se notar que a saudação é expressa pelo verbo Greco-copta acnaze.

${ }^{44}$ Tradução feita diretamente do copta pelo autor do presente artigo. Deve-se notar que, de maneira semelhante ao Apocalipse de Paulo, a ideia de saudação é expressa pelo verbo Greco-copta acnaze.
} 
24-29). ${ }^{45} \mathrm{O}$ que se segue ao relato são lacunas, mas logo depois o texto informa sobre a grandeza

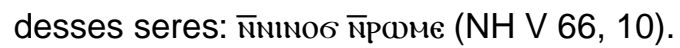

Algumas hagiografias coptas da Antiguidade tardia também contêm relatos sobre três seres celestes fantásticos. Em geral, esses seres são identificados com personagens célebres do Antigo ou do Novo Testamento. É o caso, por exemplo, de um fragmento da Vida de Pacômio preservado no dialeto saídico do copta, o fragmento $S^{1}$. Num determinado momento, esse fragmento conta que Pacômio viu três seres celestes que vieram buscar a alma de um monge que acabara de morrer: "Ele olhou e viu três homens, luminosos, eminentes, gloriosos e de cabelos grisalhos que vieram levar o homem doente. Estando ele impressionado, o anjo the disse: 'esses sãos os patriarcas Abraão, Isaac e Jacó'. E imediatamente eles levaram a alma do irmão doente, arrebatando-a ao céu com grande glória" $\left(\mathrm{S}^{1} \S 28\right)$.

Assim sendo, ao ler sobre esses três seres aparecendo nos sonhos de Adão, os leitores coptas da Antiguidade tardia não veriam nada de estranho ou herege; muito pelo contrário, encontrariam um motivo literário relativamente conhecido na literatura copta da Antiguidade tardia. Além do mais, a identificação desses seres com personagens conhecidos fazia parte do horizonte de expectativas desses leitores, o que os levaria, possivelmente, a pensar que os seres fantásticos do Apocalipse de Adão fossem personagens bíblicos importantes.

\section{Conclusão}

Exemplos desse tipo multiplicam-se nas páginas do Codex $\mathrm{V}$ e das hagiografias preservadas em copta, que certamente circulavam no Egito da Antiguidade tardia. Consequentemente, é bastante provável que os leitores coptas da Antiguidade tardia - que seguramente conheciam os textos que circulavam em copta, em especial as hagiografias, e seus temas apocalípticos interpretassem os textos do Codex V não de acordo com doutrinas e conceitos ditos gnósticos, mas de acordo com o conhecimento prévio adquirido por meio dos textos que liam, como, por exemplo, as citadas hagiografias. Assim sendo, ao lerem sobre um ancião luminoso no sétimo céu no Apocalipse de Paulo ( $\mathrm{NH} \mathrm{V} \mathrm{22,} \mathrm{25-30),} \mathrm{os} \mathrm{leitores} \mathrm{coptas} \mathrm{que} \mathrm{tiveram} \mathrm{contato} \mathrm{com} \mathrm{o} \mathrm{Codex} \mathrm{V}$ provavelmente não pensavam no deus criador das Escrituras judaicas - como pensaria um

45 Tradução feita diretamente do copta pelo presente autor. Trata-se de um texto gnóstico, vale lembrar, portanto, que o deus ao qual o trecho se refere não se trata do Deus supremo, mas daquele que para os gnósticos era apenas o criador do mundo material. Assim sendo, o fato de esses três seres não pertencerem ao deus criador significa, grosso modo, que eles são originários das esferas celestes superiores. 
"gnóstico" do séc. II; mas provavelmente na imagem de outros seres luminosos apresentados nos textos monásticos coptas, como São Pacômio, por exemplo. ${ }^{46}$

Desse modo, poder-se-ia postular, a partir desses paralelos e contatos literários, que os cristãos coptas da Antiguidade tardia se interessaram pelos textos do Codex $\mathrm{V}$ - e possivelmente pelos textos de Nag Hammadi em geral - não necessariamente devido às doutrinas expostas em seus textos, mas devido aos temas literários encontrados nesses próprios textos e nos demais tipos de literatura que eles conheciam e consumiam, na maioria das vezes, textos monásticos. Assim sendo, os donos dos textos de Nag Hammadi no Egito do séc. IV - em especial os do Codex V não seriam gnósticos infiltrados em mosteiros, ou heresiólogos, mas apenas cristãos interessados em textos que narravam aventuras míticas de heróis bíblicos - como Paulo, Tiago e Adão - fazendo uso dos mesmos temas e motivos literários que eles conheciam profundamente por meio de textos coptas.

Como mencionado no início do presente artigo, poucas regiões do Império Romano legaram aos historiadores de hoje tantos textos e manuscritos cristãos quanto o Egito. A quantidade de manuscritos é tamanha que muita coisa sequer foi editada ou publicada; incontáveis manuscritos permanecem nas bibliotecas europeias, norte-americanas e orientais aguardando quem quer que queira se aventurar no fantástico mundo da restauração e edição de manuscritos. Além da quantidade de manuscritos, a diversidade de abordagens está igualmente aberta a novas aventuras - como a proposta desse artigo tentou elucidar. A literatura e os manuscritos do Egito da Antiguidade tardia, tanto os ditos "gnósticos" quanto, de maneira mais geral, os cristãos, aguardam por novos historiadores e cientistas das religiões que se prestem a tal tarefa.

\section{Referências}

ADLER, William. Introduction. In: VANDERKAM, James; ADLER, William (Org.). The Jewish Apocalyptic Heritage in Early Christianity. Compendia Rerum ludiacorum ad Novum Testamentum 4. Assen/Minneapolis: Van Gorgum/Fortress Press, 1996. p. 1-31.

BAGNALL, Roger. Early Christian Books in Egypt. Princeton/Oxford: Princeton University Press, 2009.

BALDICK, Chris. Oxford Dictionary of Literary Terms. Oxford/New York: Oxford University Press, 2008.

${ }^{46}$ Assim descrito, por exemplo, em um dos fragmentos em copta saídico $\left(\mathrm{S}^{6}\right)$ da Vida de Pacômio e na Vida Boarídica de Pacômio (SBo § 144). 
BARNS, John. Greek and Coptic Papyri from the Covers of the Nag Hammadi Codices: a Preliminary Report. In: KRAUSE, Martin (Org.). Essays on the Nag Hammadi Texts in Honour of Pahor Labib. Nag Hammadi Studies 6. Leiden: E.J. Brill, 1975. p. 9-18.

BARNS, John; BROWNE, Gerald M.; SHELTON, John C. (Org.). Nag Hammadi Codices. Greek and Coptic Papyri from the Cartonnage of the Covers. Nag Hammadi Studies 16. Leiden: E.J. Brill, 1981.

BAUMEISTER, Theofried. Martyr Invictus: Der Martyrer als Sinndild der Erlösung in der Legende und im Kult der frühen koptischen Kirche. Münster: Regensberg, 1972.

BLUMMEL, Lincoln H. Lettered Christians: Christians, Letters and Late Antique Oxyrhynchus. Leiden/Boston: E.J. Brill, 2012.

COLLINS, Jonh J. (Org.). Apocalypse: The Morphology of a Genre. Semeia 14. Atlanta: Society of Biblical Literature, 1979.

DIAS CHAVES, Julio Cesar. Neo-platonismo, apocalíptica e gnose: os apocalipses filosóficos setianos. Oracula, São Bernardo do Campo, v. 6, p. 114-129, 2007.

DIAS CHAVES, Julio Cesar. Between Apocalyptic and Gnosis: The Nag Hammadi Apocalyptic Corpus. Delimitation and Analysis. Saarbrücken: Lambert Academic Publishing, 2010.

DIAS CHAVES, Julio Cesar. Le codex V de Nag Hammadi et la littérature copte du 4e siècle : une approche comparative. In: RENCONTRE DOCTORALE SUR L ANTIQUITÉ, 2011, Québec. Comunicação ... Québec: Université Laval, 2011.

DIAS CHAVES, Julio Cesar. A Gnose em Questão: Ensaios sobre Gnose e Apocalíptica na Antiguidade e a Biblioteca Copta de Nag Hammadi. Curitiba: Ed. Prismas, 2015a.

DIAS CHAVES, Julio Cesar. Judas, herói ou traidor: o Evangelho de Judas do Codex Tchacos. In: DIAS CHAVES, Julio Cesar; DOBRORUKA, Vicente. Espectadores do Sagrado: Experiência Visionária e Apócrifos do Novo Testamento. Brasília: Ed. UnB, 2015b. p. 255-286.

DIAS CHAVES, Julio Cesar. Reading Nag Hammadi Codices in Late-antique Egypt: Some Methodological Issues in Light of the Theory of Reception. In: SEMINÁRIO INTERNACIONAL NAG HAMMADI À 70 ANS: Qu'avons nous appris?, 2015, Québec. Comunicação... Québec: Université Laval, 2015c.

DORESSE, Jean. Les Livres secrets de gnostiques d'Égypte. Paris: Plon, 1958.

DORESSE, Jean. Les reliures des manuscrits gnostiques coptes découverts à Khénoboskion. Revue d'Égypte, v. 13, p. 27-49, 1961. 
EMMEL, Stephen. Religious Tradition, Textual Transmission, and the Nag Hammadi Codices. In: TURNER, John; MAQUIRE, Anne (Org.). The Nag Hammadi Library after Fifty Years. Leiden/New York: E. J. Brill, 1997. p. 34-43.

GAMBLE, Harry I. Books and Readers in the Early Church. New Heaven/London: Yale University Press, 1995.

GOEHRING, James. Ascetics, Society, and the Desert: Studies in Egyptian Monasticism. Harrisburg: Trinity Press International, 1999.

HAINES-EITZEN, Kim. Guardians of Letters: Literacy, Power and the Transmitters of Early Christian literature. Oxford/New York: Oxford University Press, 2000.

HEDRICK, Charles. Gnostic Proclivities in the Greek Life of Pachomius and the Sitz im Leben of the Nag Hammadi Library. Novum Testamentum, v. 22, n. 1, p. 78-94, 1980.

HOLUB, Robert C. Reception Theory: a Critical Introduction. Londres/Nova York: Methuen, 1984.

JAUSS, Hans R. Pour une esthétique de la réception. Paris: Gallimard, 1978.

JENOTT, Lance; PAGELS, Elaine. Antony's Letters and Nag Hammadi Codex I: Sources of Religious Conflict in Fourth-Century Egypt. Journal of Early Christian Studies, v. 18, n. 4, p. 557-589, 2010.

JENOTT, Lance. Recovering Adam's Lost Glory: Nag Hammadi Codex II in its Egyptian Monastic Environment. In: JENOTT, Lance; GRIBETZ, Sarit Kattan (Org.). Jewish and Christian Cosmogony in Late Antiquity. Texts and Studies in Ancient Judaism. Tübingen: Mohr Siebeck, 2013. v. 155, p. 222-236.

JONAS, Hans. The Gnostic Religion. Boston: Beacon Press, 1958.

KING, Karen. What is Gnosticism. Cambridge: Harvard University Press, 2003.

KHOSROYEV, Alexander. Die Bibliothek von Nag Hammadi: Einige Probleme des Christentums in Ägypten während der ersten Jahrhunderte. Altenberge: Oros Verlag, 1995.

LUNDHAUG, Hugo; JENOTT, Lance. The Monastic Origins of the Nag Hammadi Library. Tübingen: Mohr Siebeck (no prelo).

MILNE, Hebert J.M.; SKEAT, Theodore C. The Codex Sinaiticus and the Codex Alexandrinus; with Seven Illustrations. Londres: British Museum, 1963.

MORARD, Françoise. Les Apocalypses du codex $\mathrm{V}$ de Nag Hammadi. In: PAINCHAUD, Louis; PASQUIER, Anne (Org.). Les Textes de Nag Hammadi et le problème de leur classification. 
Québec/Louvain: Les Presses de I'Université Laval/Peeters, 1995. p. 341-357. (Bibliothèque copte de Nag Hammadi section «études» 3).

ORLANDI, Tito. A Catechesis Against Apocryphal Texts by Shenoute and the Gnostic Texts of Nag Hammadi. In: Harvard Theological Review, v. 75, n. 1, p. 85-95,1982.

PAINCHAUD, Louis. La production et la destination du codex III de Nag Hammadi. In: SEMINÁRIO INTERNACIONAL NAG HAMMADI À 70 ANS: Qu'avons nous appris?, 2015, Québec. Comunicação... Québec: Université Laval, 2015.

PAINCHAUD, Louis. The Production and Destination of the Nag Hammadi Sub-Collections. In: LUNDHAUG, Hugo; JENOTT, Lance (Org.). The Nag Hammadi Codices in the Context of Fourthand-Fifth Century Christianity in Egypt. Tübingen: Mohr Siebeck (no prelo).

PEARSON, Birger. The Emergence of the Christian Religion. Harrisburg: Trinity Press International, 1997.

POIRIER, Paul-Hubert. La Bibliothèque copte de Nag Hammadi: sa nature et son importance. Studies in Religion, Sceinces religieuses, v. 15, n. 3, p. 303-316, 1986.

ROBINSON, James. The Nag Hammadi Codices - A General Introduction to the Nature and Significance of the Coptic Gnostic Library from Nag Hammadi. Claremont: The Institute for Antiquity and Christianity, 1974.

ROBINSON, James. From the Cliff to Cairo. In: BARC, Bernard (Org.). Colloque international sur les textes de Nag Hammadi. Bibliothèque copte de Nag Hammadi section «études "1. Québec: Les Presses de l'Université Laval, 1981. p. 21-58.

ROBINSON, James. The Facsimile Edition of The Nag Hammadi Codices. Leiden: E.J. Brill, 1984.

ROBINSON, James. The Manichaean Codices of Medinet Madi. Eugene: Cascade Books, 2013.

ROSENSTIEHL, Jean-Marc; KALER, Michael. L'Apocalypse de Paul. Québec/Louvain: Les Presses de I'Université Laval/Peeters, 2005. (Bibliothèque copte de Nag Hammadi section «textes» 31).

ROUSSEAU, Philip. Pachomius: The Making of a Community in Fourth Century Egypt. Berkley/Los Angeles: University of California Press, 1985.

SÄVE- SÖDERBERGH, Torgny. Holy Scriptures or Apologetic Documentation? The Sitz im Leben of the Nag Hammadi Library. In: MÉNARD, Jacques.-É. (Org.). Les Textes de Nag Hammadi. Nag Hammadi Studies 7. Leiden: E.J. Brill, 1975. p. 9-17.

SCHOLTEN, Clemens. Die Nag-Hammadi-Texte als Buchbesitz der Pachomianer. Jahrbuch für Antike und Christentum, v. 31, p. 144-172, 1988. 
VAN DER VLIET, Jacques. The Coptic Gnostic Texts as Christian Apocryphal Literature. In: EMMEL, Stephen et al. (Org.). Ägypten und Nubien in spätantiker und christlicher Zeit. Akten des 6. Internationalen Koptologenkongresses Münster. v.2: Sprache, Schrifttum und Gedankenwelt. Sprachen und Kulturen des Christlichen Orients. Berlim: Wiesbaden, 1999. p. 553-562.

VAN REGEMORTER, Berthe. La reliure des manuscrits gnostiques découverts à Nag Hammadi. Scriptorum, v. 14, p. 225-234, 1960.

VEILLEUX, Armand. Monachisme et gnose. Première partie: Le cénobitisme pachômien et la bibliothèque copte de Nag Hammadi. Laval théologique et philosophique, v. 40, n. 3, p. 275-294, 1984.

VEILLEUX, Armand. Monachisme et gnose. Deuxième partie: Contacts littéraires et doctrinaux entre monachisme et gnose. Laval théologique et philosophique, v.41, n. 1, p. 3-24, 1985.

WILLIAMS, Michael. Rethinking Gnosticism: An Argument for Dismantling a Dubious Category. Princeton: Princeton University Press, 1996.

WIPSZYCKA, Ewa. Moines et communautés monastiques en Égypte (IVe - VIIle siècles). Varsóvia: Journal of Juristic Papyrology, 2009.

WISSE, Frederick. Gnosticism and Early Monasticism in Egypt. In: ALAND, Barbara (Org.). Gnosis: Festschrift für Hans Jonas. Göttingen: Vandenhoeck \& Ruprecht, 1978. p. 431-440.

WISSE, Frederick. Language Mysticism in the Nag Hammadi Texts and in Early Coptic Monasticism I: Cryptography. Enchoria, v. 9, p. 101-120, 1979.

Recebido em 29.07.2015 - aprovado em 18.09.2015 